\title{
ANÁLISE GEOECOLOGICA DA UGHRI-22 E OS IMPACTOS AMBIENTAIS OCASIONADOS PELA DISPOSIÇÃO INADEQUADA DE RESÍDUOS SÓLIDOS
}

\author{
Lucas Prado Osco ${ }^{1}$, Marcos Norberto Boin ${ }^{2}$ \\ ${ }^{1}$ Engenheiro Ambiental, pela UNOESTE, Aluno Especial do Mestrado em Meio Ambiente - UNOESTE. ${ }^{2}$ \\ Docente do Mestrado em Meio Ambiente - UNOESTE. E-mail: lucas prado 123@hotmail.com
}

\section{RESUMO}

O presente trabalho, intitulado de "Análise geoecologia da UGHRI-22 e os impactos ambientais ocasionados pela disposição inadequada de resíduos sólidos" tem por objetivo apresentar um levantamento de estudos referentes as geoecologia da paisagem nos municípios da UGHRI-22, com a finalidade de apontar as características ambientais e os impactos ocasionados pela disposição destes resíduos sólidos sobre os mesmos. Deve-se, portanto, elaborar uma discussão em razão da vulnerabilidade que o ecossistema apresenta diante da disposição a materiais contaminantes, relacionando as condições geoecológicas da região e considerando sua vulnerabilidade diante dos agentes contaminantes.

Palavras-chave: Meio Ambiente; Impactos; Oeste Paulista; UGHRI-22.

\section{INTRODUÇÃO E OBJETIVO}

Ao abordar o termo meio ambiente, este demonstra certa notabilidade por ser extremamente difundido dentre diversas discussões, aplicando-se a conjuntos e teorias disseminadas por meio das mais amplas áreas do conhecimento científico. A Política Nacional de Meio Ambiente (PNMA), eu seu Art. 3, apresenta um conceito geral de meio ambiente, considerando este como "[...] o conjunto de condições, leis, influências e interações de ordem física, química e biológica, que permite, abriga e rege a vida em todas as suas formas [...]”. A este conjunto se apresenta uma série de pesquisas e fundamentos relacionados à questão ambiental, como também, consta-se uma abordagem ampla em relação aos impactos ambientais.

De acordo com a NBR ISO 14.004 (2004), um impacto ambiental é definido como: "qualquer mudança no ambiente, quer adversa ou benéfica, inteira ou parcialmente resultante das atividades, produtos ou serviços de uma organização". Desta forma, é importante abordar o conceito de impacto ambiental, pois este difere do que é conhecido como dano ambiental, por apresentar uma condição tanto benéfica quanto maléfica. Ao que diz respeito pelo entendimento de dano ambiental, este abrange às condições desastrosas, resultando em degradações ambientais. Para Sánchez (2008), a degradação ambiental não passa de um termo de conotação negativa, sendo geralmente uma redução de condições naturais ou do estado de um determinado ambiente. 
Práticas antrópicas, sendo danosas ou não, quando aplicadas ou redirecionadas ao meio ambiente, resultam em uma alteração ao seu conjunto de características. Dentre aquelas que realizam mudanças desastrosas está a questão dos resíduos sólidos, proveniente do descarte de materiais previamente utilizados pelo ser humano. Consoante à Política Nacional de Resíduos Sólidos (PNRS), os resíduos sólidos são definidos como todo material ou substância que apresentam características de reutilização, reciclagem e tratamento, já os rejeitos são os resíduos que, depois de esgotadas todas as possibilidades de tratamento, têm como último recurso à disposição final ambientalmente adequada.

A destinação dos resíduos sólidos é atribuída, de acordo com a PNRS, à responsabilidade de seus geradores, assim como ao poder público, a incumbência de adequar os resíduos provenientes do município a um gerenciamento ambientalmente correto. Dentre as práticas relacionadas à destinação dos resíduos está à redução em sua produção, à reciclagem, trazendo o produto a um novo ciclo de vida e também à reutilização, consistindo no reaproveitamento dos materiais. Entretanto, resíduos e rejeitos, quando diferenciadas suas classificações, possuem uma destinação específica. Aquilo que é considerado como rejeito ou inservível é direcionado ao aterro sanitário, enquanto que os demais são redirecionados ao reaproveitamento ou reciclagem.

Os impactos ambientais ocasionados pela disposição de resíduos em aterros em vala ou lixões, de forma inadequada, podem resultar em implicações ao meio ambiente, tornandose assim uma degradação ambiental, contaminando o solo, o ar, as águas subterrâneas e as superficiais. No Estado de São Paulo, a problemática dos resíduos sólidos tornou-se alvo de preocupação diante da comunidade científica e ambiental. As condições do tratamento dos resíduos sólidos no Estado de São Paulo apresentam algumas inconformidades quanto aos instrumentos estabelecidos pela PNRS, principalmente no oeste paulista. É evidente, portanto a necessidade de se planejar uma melhor gestão integrada dos resíduos sólidos no Pontal do Paranapanema, por parte do poder público, com a finalidade de resolver e adequar à disposição final de acordo com as normas estabelecidas.

A disposição atual dos resíduos sólidos na UGRHI-22 está nos denominados lixões ou, em alguns casos, em aterros em valas (controlados). Desta forma, os resíduos sólidos representam um sério risco de poluição e consequentemente um dano ambiental, ao qual se faz necessário o estudo de sua área de disposição e seus consequentes impactos sobre o subsolo, o solo, os recursos hídricos, o ar, o relevo e a paisagem. De acordo com a SEADE (1999), daqueles 
aspectos de maior interferência às condições ambientais da UGRHI-22, a erosão de solos urbanos e rurais é tida como a maior problemática a ser enfrentada, contribuindo para o assoreamento de rios e córregos. A UGRHI-22 é caracterizada por solos arenosos (Grupo Bauru), formados em bacia sedimentar, aos quais estes, por serem susceptíveis a infiltrações, resultam em uma série de consequências quando recebem depósitos de resíduos, pois irão apresentar interações com o meio ambiente. O estudo, portanto, concentra-se na caracterização geológica, pedológica, geomorfológicas, hidrogeológica e climática dos municípios localizados na UGRHI-22.

\section{METODOLOGIA}

A metodologia utilizada no presente trabalho constitui de um levantamento bibliográfico referente a estudos e trabalhos com uma abordagem em relação à caracterização ambiental, como ecologia, ecossistema, ecodinâmica, teoria geral dos sistemas e geoecologia da paisagem. Para isto buscou-se analisar diversos trabalhos e publicações referentes ao quadro geoecológico regional, assim como uma análise geral dos impactos ambientais provocados pela disposição inadequada de resíduos sólidos em contato com o ambiente. Com isto, o artigo tem por finalidade elaborar uma discussão referente aos aspectos e vulnerabilidades do meio físico da região do Pontal do Paranapanema.

\section{RESULTADOS}

Como resultado foi realizado pesquisa bibliográfica sobre os aspectos geoecológicos da UGRHI-22, que passamos a destacar a seguir.

\section{Aspecto Geológico}

Na região da UGRHI-22, a Bacia Sedimentar do Paraná é composta por coberturas cenozoicas, pelas Formações Marília, Adamantina, Santo Anastácio, Caiuá e Serra Geral. De acordo com Cabral (1991), a bacia do Paraná pode ser considerada uma bacia que apresenta um comportamento relativamente estável, sendo esta dissociada de efeitos tectono-térmicos mais agudos quando em comparação com outras bacias localizadas à margem continental. Trata-se, portanto, de uma bacia intracratônica sul-americana, ao qual seu desenvolvimento deu-se totalmente sobre a crosta continental, abrangendo como registro lítico-sedimentar o magmático do Mesopaleozóico ao Cenozóico. A coluna litoestratigráfica da bacia do Paraná, de acordo com o IPT (1981), apresenta formações geológicas dominantes na região da UGHRI-22 que pertencem ao 
Grupo São Bento, composto pela Formação Serra Geral e ao Grupo Bauru, consistindo nas Formações Caiuá, Santo Anastácio, Adamantina, e os Depósitos Cenozóicos.

Segundo o IPT (1981a), a Formação Serra Geral pode ser definida como uma formação constituída por rochas vulcânicas toleíticas, que estão dispostas em derrames basálticos. Estas apresentam uma coloração cinza ou negra, uma textura afanítica, com intercalações de arenitos intertrapeanos, finos a médios, aos quais apresentam uma estratificação cruzada tangencial. Já a Formação Caiuá é constituída por arenitos de finos a médios, dos quais possuem grãos arredondados, com uma coloração arroxeada típica, ao mesmo tempo em que apresentam abundantes estratificações cruzadas de médio a grande porte. A Formação Santo Anastácio, por sua vez, apresenta arenitos de muito finos a médios, sendo estes mal selecionados e subordinadamente de caráter arcosiano, de forma maciça, apresentando localmente cimento e nódulos carbonáticos.

Quando abordado os aspectos presentes na UGHRI-22, a Formação Adamantina apresenta-se como a de maior importância para a região, pois constituí a maior parte do território. De acordo o IPT (1981a), a Formação Adamantina é formada por arenitos de finos a muito finos, com cimentação e nódulos carbonáticos com lentes de sílitos arenosos e também argilíticos, que ocorrem em bancos maciços e sua estratificação plano-paralela é cruzada de pequeno a médio porte.

\section{Aspecto Geomorfológico}

De acordo com o IPT (1981b), em seu Mapa Geomorfológico do Estado de São Paulo (IPT, 1981b), o Estado de São Paulo apresenta-se dividido em cinco províncias geomorfológicas, estas províncias recebem as seguintes denominações: Planalto Atlântico; Província Costeira; Depressão Periférica; Cuestas Basálticas e Planalto Ocidental Paulista. A UGHRI-22, geomorfologicamente, está localizada no Planalto Ocidental Paulista, ao qual abrange aproximadamente uma área de 50\% de todo o Estado de São Paulo. Esta província apresenta, por meio do espesso pacote vulcânico-sedimentar da Bacia do Paraná, a disposição das camadas com um leve caimento ao sentindo noroeste, além da presença de um marcado horizonte de basaltos, que separam as rochas paleozoicas e mesozoicas inferiores.

Segundo Nunes (2002), a constituição do Planalto Ocidental é representada pela continuidade física do reverso das Cuestas Basálticas, limitadas a leste. O relevo desta província está subordinado à estrutura regional, as quais suas camadas sub-horizontais apresentam um 
suave caimento à direção oeste, constituindo uma plataforma nivelada em cotas, das quais atingem a foz do rio Paranapanema. O embasamento deste Planalto Ocidental está constituído por rochas do Grupo Bauru, ao qual em sua maioria arenitos, apresentando cimento carbonático ou silicoso.

Na região da UGHRI-22, ainda de acordo com o mesmo autor (Nunes, 2002), o Planalto Ocidental apresenta uma drenagem organizada por rios consequentes, predominantemente, aos quais apresentam um desenvolvimento interno aos limites da província. A rede de drenagem, portanto, demonstra um paralelismo de eixos na direção NW-SE, apresentando planícies aluviais de diferentes dimensões. A drenagem demonstra diversas variações de padrão devido aos sistemas de relevo, sendo estas em maiores proporções na região das cabeceiras, próximas aos divisores de águas principais, que possuem um numero de ramificações de drenagem elevado.

\section{Aspecto Pedológico}

Referente às características do solo, o mesmo pode apresentar comportamentos diferentes devido à origem de sua composição, tendo esta como fator importante ao se atribuir uma classificação. Há um conjunto de influências que resultam na avaliação da capacidade de uso de um solo, pois apresentam uma caracterização das condições do solo. Dentre estas influências podemos citar como exemplos os níveis de infiltração, permeabilidade e vulnerabilidade. Assim, uma verificação de sua constituição textura, estrutural e mineralógica, é indispensável para determinação desta capacidade. Segundo a CNEPA (Comissão de Solos do Centro Nacional de Ensino e Pesquisa Agronômica, 1960 apud CPIT, 1999), na região do oeste paulista, identificam-se quatro tipos de solos: latossolos vermelho escuro; terra roxa estruturada; podzólico (argissolo), solos hidromórficos (glei). Estes são solos resultantes de processos pedogenéticos decorrentes de rochas areníticas pertencentes ao Grupo Bauru e de rochas basálticas do Grupo São Bento.

De acordo com a CPTI (1999), o latossolo vermelho escuro corresponde a aqueles solos minerais considerados como não hidromórficos, com horizonte latossólico e uma coloração vermelha escura. Sua textura varia de argilosa a média, ao mesmo em que apresenta uma íntima relação com o substrato pedogenético em razão as suas características granulométricas e mineralógicas. Este solo apresenta alta drenagem ao longo de seu perfil. De acordo com a SMA (1999), este tipo de solo pode ser encontrado nos municípios de Teodoro Sampaio, Euclides da Cunha Paulista, Rosana, Presidente Epitácio, Sandovalina, Tarabai, sul de Santo Anastácio, norte 
de Mirante do Paranapanema, Nantes, lepê e sul de Rancharia. A terra roxa estruturada compreende os solos minerais não hidromórficos com horizonte textural, sendo estes relativamente profundos, apresentando uma baixa drenagem e uma textura argilosa, com gradiente textural baixo. Tendo ocorrência restrita nos reservatórios de Capivara e Taquaruçu, ao sul de lepê, Nantes, Taciba e Narandiba.

O solo podzólico (argissolo), por sua vez, apresenta como característica drenagem moderada, variando entre rasos e profundos, com textura arenosa/média à argilosa/muito argilosa. Sua relação textural também apresenta variações, decorrendo de solos com mudanças texturais abruptas, até em solos com baixa variação no teor de argila ao longo do seu perfil. O glei é comporto por solos hidromórficos, ao qual apresentam má drenagem, além de uma intensa redução de ferro durante o seu desenvolvimento, que fica evidenciado por cores neutras ou então muito próximas de neutras na matriz do solo, com ou sem mosqueado. De acordo com a SMA (1999), as localidades as quais apresentam esta composição pedológica são: a oeste de Rosana, ao longo do rio Santo Anastácio ao longo dos ribeirões Nhanca, Engano e do rio Pirapozinho no município de Mirante do Paranapanema, do ribeirão Anhumas, em Narandiba; Ribeirão da Laranja Doce, em Taciba.

\section{Aspecto Climatológico}

Ao que se refere ao clima da região da UGHRI-22, este recebe, de acordo com a classificação climática de Köppen, o conjunto de efeitos atribuídos à uma parte de clima temperado brando, verões quentes e chuvosos, e outra parte, compreendida em um clima temperado brando, com um verão fresco e chuvoso. Já segundo a classificação de Boin (2000), a UGHRI-22 está dividida em três unidades climáticas, denominadas de BIIIm, BIVma e BIVm $\beta$, onde as chuvas são provocadas, principalmente, pelos mecanismos frontológicos engendrados pela participação da massa Polar Atlântica, que se confrontam com a massa Tropical Atlântica, também presente nestas unidades. Segundo a CPTI (1999), a grande parte da bacia pode ser caracteriza por seu clima temperado, apresentando temperaturas de seu mês mais frio entre $18^{\circ} \mathrm{C}$ e $-3 \stackrel{\circ}{ } \mathrm{C}$, ao qual a temperatura média do mês mais quente é superior a $22^{\circ} \mathrm{C}$.

\section{Aspecto Hidrogeológico}

Por importância do estudo hidrogeológico, deve levar-se em consideração os impactos realizados em áreas onde estão implantados aterros ou lixões, pois estes apresentam 
comportamentos de contaminação perante as características hidrogeológicas do local. Há um inúmero conjunto de processos físico-químicos e biológicos que atuam na paisagem influenciando nas características do corpo d'água, alterando o fluxo subterrâneo, ao qual a água percorre por meio de poros e fraturas no solo e rochas, transportando elementos dissolvidos ou em solução. De acordo com Nunes (2002), o oeste paulista apresenta como principais aquíferos, o Bauru/Caiuá e a Serra Geral. Na UGHRI-22 à ocupação do aquífero Bauru/Caiuá em sua maior parte, subdividindose em unidade aquífera Bauru Médio/Superior e Bauru Inferior/Caiuá, ambas apresentando grande diferença relacionada a permeabilidade e transmissividade aparente. No entanto, embora que localmente há condições para a formação de aquíferos semiconfinados, regionalmente, seja na unidade superior ou inferior, há uma predominância de condições de aquífero livre.

\section{DISCUSSÃO}

O estudo das características da paisagem em uma região é de extrema importância, pois proporciona condições e base para a elaboração de quaisquer trabalhos que envolvam contato com o meio físico. Ao analisar os aspectos geoecológicos e ecossistêmicos, é possível determinar a capacidade de exploração de seus recursos naturais, além da contribuição que este representa para o ser humano. Por meio desta caracterização é possível determinar: as litologias, os tipos de solos, relevo local, textura e condutividade hidráulica do aquífero e sua vulnerabilidade. Estas características ambientais proporcionam condições para uso dos recursos naturais, além de indicar critérios para contenção de poluentes.

O meio ambiente, quando degradado, é sensível aos impactos ambientais adversos com pouca capacidade de recuperação à contaminação decorrente de atividades humanas. Neste sentido, a destinação incorreta dos resíduos sólidos torna-se um dos principais problemas a serem enfrentados na defesa do desenvolvimento sustentável. Por conta das formações geológicas, pedológicas e geomorfológicas, o solo presente na UGHRI-22 apresenta alta permeabilidade por ter em sua maior composição granulométricas frações arenosas. A presença de resíduos sólidos em um ambiente como o da UGHRI-22, representa um risco, pois esta é uma região que naturalmente é fragilizada pela sua constituição geoecológica. Portanto, a disposição de resíduos neste meio contribui para a contaminação dos recursos naturais, principalmente no que diz respeito aos recursos hídricos, pois por conta dos fatores climáticos e hidrogeológicos descritos anteriormente, boa parte dos contaminantes resultantes desta disposição, terão como destino os lençóis freáticos da bacia do Pontal do Paranapanema. 


\section{CONCLUSÃO}

A disposição de resíduos sólidos, quando incorreta, resulta em sérias consequências para o meio físico. Diante das características encontradas na UGHRI-22, a as condições geoecológicas proporciona maior vulnerabilidade à contaminação provocada por poluentes. As formações presentes são propícias a infiltrações que dificultam a recuperação natural. Os impactos ocasionados por resíduos sólidos devem receber a devida atenção devido aos problemas decorrentes de sua atividade, sendo a contaminação dos recursos naturais (solo, água e ar) o principal deles, provocado pela formação de chorume. Uma vez que a água da chuva entre em contato com os detritos dos resíduos, deverá percolar pelo solo, transportando contaminantes para os recursos hídricos da bacia. Estes contaminantes são prejudiciais não só a biodiversidade, como também a saúde pública, e afetando ainda questões econômicas, tornando o tratamento da água contaminada mais caro. Assim, é válida a elaboração de estudos que busquem contextualizar as condições físicas da região, para que desta forma reforce no auxílio da tomada de decisões e projetos de recuperação ou reparação dos danos ocasionados.

\section{REFERÊNCIAS}

ABNT - Associação Brasileira de Normas Técnicas. NBR 10004. Resíduos Sólidos - Classificação. Rio de Janeiro: ABNT, 2004.

BRASIL. Lei $n^{\circ}$ 6.938, de 31 de agosto de 1981. Dispõe sobre a Política Nacional do Meio Ambiente, seus fins e mecanismos de formulação e aplicação, e dá outras providências.

BRASIL. Lei $n^{\circ}$ 12.305, de 02 de agosto de 2010. Institui a Política Nacional de Resíduos Sólidos; altera a Lei $n^{\circ}$ 9.605, de 12 de fevereiro de 1998; e dá outras providências.

BOIN, M. N. Chuvas e erosões no oeste paulista: uma análise climatológica aplicada. Tese de Doutorado. IGCE. Rio Claro - SP. 264p. 2000.

CPTI - Cooperativa de Serviços e Pesquisas Tecnológicas e Industriais. Relatório Zero da bacia hidrográfica do Pontal do Paranapanema. São Paulo: CPTI, 1999.

CEEIPEMA - Comitê Executivo de Estudos Integrados da Bacia Hidrográfica do Rio Paranapanema. 1981. Caracterização e definição do uso do solo do Paranapanema - caracterização do clima. Relatório n.2, fevereiro de 1981.

IPT - Instituto de Pesquisas Tecnológicas do Estado de São Paulo. 1981a. Mapa Geológico do Estado de São Paulo, 1:500.000. São Paulo, IPT. v. 2.

IPT - Instituto de Pesquisas Tecnológicas do Estado de São Paulo. 1981b. Mapa Geomorfológico do Estado de São Paulo, 1:1.000.000. São Paulo, IPT. v. 2. 
NUNES, J. O. R. Uma contribuição metodológica ao estudo da dinâmica da paisagem aplicada a escolha de áreas para construção de aterro sanitário em Presidente Prudente. 2002. $211 \mathrm{f}$. Tese (Doutorado em Geografia) - Faculdade de Ciência e Tecnologia, Universidade Estadual Paulista. Presidente Prudente.

SÁNCHEZ, L. E. Avaliação de Impacto Ambiental: Conceitos e métodos. São Paulo: Oficina de Textos, 2008.

SÃO PAULO (ESTADO)/SMA-SEADE. Dinâmica Sócio-Econômica das Unidades de Gerenciamento de Recursos Hídricos do Estado de São Paulo - UGRHI 22 - Pontal do Paranapanema. São Paulo, 1999. 